\title{
MANAGEMENT OF URINARY TRACT INFECTION BY EARLY-CAREER GENERAL PRACTITIONERS IN AUSTRALIA
}

Running title: Management of UTI

Abstract word count: $(\max 300) 283$

Manuscript word count: (5000) 2998

\section{Authors:}

Andrew Davey ${ }^{1,2}$

Amanda Tapley ${ }^{1,2}$

Katie Mulquiney ${ }^{1,2}$

Mieke van Driel ${ }^{3}$

Alison Fielding ${ }^{2}$

Elizabeth Holliday ${ }^{1,4}$

Jean Ball ${ }^{4}$

Neil Spike

Kristen FitzGerald ${ }^{6,7}$

Parker Magin ${ }^{1,2}$

1. University of Newcastle, NSW, Australia

This is the author manuscript accepted for publication and has undergone full peer review but has not been through the copyediting, typesetting, pagination and proofreading process, which may lead to differences between this version and the Version of Record. Please cite this article as doi: $10.1111 /$ jep.13340

This article is protected by copyright. All rights reserved. 
2. GP Synergy, Regional Training Organisation, NSW, Australia

3. University of Queensland, QLD, Australia

4. Hunter Medical Research Institute, NSW, Australia

5. Eastern Victoria General Practice Training, Regional Training Organisation, VIC, Australia

6. University of Tasmania, TAS, Australia

7. General Practice Training Tasmania, Regional Training Organisation, TAS, Australia

\title{
Corresponding author:
}

\author{
Andrew Davey \\ email: andrew_davey@gpsynergy.com.au
}




\section{MANAGEMENT OF URINARY TRACT INFECTION BY EARLY-CAREER GENERAL PRACTITIONERS IN AUSTRALIA}

\section{ABSTRACT}

\section{Rationale, aims and objectives}

Urinary tract infection (UTI) is a common presentation to general practitioners (GPs). There is increasing antimicrobial resistance in urinary pathogens in many healthcare systems. Adherence to principles of antimicrobial stewardship is important to combat this problem. Our aim was to describe the prevalence of presentations of clinically diagnosed new urinary tract infection to earlycareer general practitioners, to describe management choices made, and identify associations of prescribing antibiotics at the index consultation for urinary tract infection.

\section{Method}

A cross-sectional analysis of the Registrar Clinical Encounters in Training cohort study. Early-career general practitioners from five Australian states (urban to very remote practices) collected data on 60 consecutive patient encounters during each of three six-month training terms. Proportions of problems being new UTIs, antibiotics prescribed, urine microscopy and culture ordered, were calculated. Univariate and multivariable logistic regression established associations of patient, registrar and practice factors with prescribing antibiotics for a new UTI.

This article is protected by copyright. All rights reserved. 


\section{Results}

1,333 early-career GPs diagnosed 2,850 new UTIs from 189,736 consultations (1.5\% [ $95 \% \mathrm{Cl} 1.4-1.6]$ ). Antibiotics were prescribed at $86 \%$ [95\% $\mathrm{Cl}$ 84.7-87.2] of these index consultations. Antibiotic choice followed Australian therapeutic guideline recommendations. Urine microscopy and culture was requested at the index consultation less than recommended by guidelines in men, $69.2 \%[95 \% \mathrm{Cl}$ 62.6-75.1], and children, $80.8 \%$ [95\% $\mathrm{Cl} 76.4-84.6]$. Adults were significantly more likely to be treated with antibiotics at the index consultation than children under 16.

\section{Conclusions}

A new UTI is a common presentation to Australian early-career GPs. There is general adherence to guidelines for antibiotic choice in UTIs. Further research is needed, however, to understand some decisions made when managing UTI in children and men. This may reflect diagnostic uncertainty with consequent attention to antibiotic stewardship by deferring antibiotic prescription.

\section{Keywords:}

Urinary tract infections; General Practitioners; Prevalence; Anti-bacterial agents; Cross-sectional studies

This article is protected by copyright. All rights reserved. 


\section{MAIN TEXT}

\section{Introduction}

Symptomatic urinary tract infection (UTI) is a common presentation to general practitioners (GP). In 2015-2016, new UTI was managed in $1.2 \%$ of Australian GP consultations, and was the $5^{\text {th }}$ most common new problem managed. ${ }^{1}$ In 2007 , UTI represented $0.9 \%$ of all ambulatory visits in the USA. ${ }^{2}$ In Canada, patients' self-reported history of physician diagnosis of one or more UTI was $12.6 \%$ per year for women and $3 \%$ per year for men. ${ }^{2}$

The most common cause of UTI is E. coli ( $51 \%$ to $73 \%$ ) followed by other bacteria such as Enterococcus, Klebsiella and Proteus species. ${ }^{3-5}$ Therefore, antibiotics are generally accepted as the standard of care for UTI but, as with any antibiotic use, creating resistance through overuse is a concern. Studies of non-antibiotic strategies for uncomplicated UTI in women concluded that although non-steroidal anti-inflammatories alone could be used in mild to moderate cases, they had inferior symptom control compared to antibiotics and there was possibly a higher risk of progressing to pyelonephritis. ${ }^{6-8}$ More worryingly recent reports have concluded that delaying antibiotics may increase bloodstream infection and all-cause mortality in community-dwelling elderly. ${ }^{9}$

There is significant antimicrobial resistance to antibiotics used for UTI: in a French study, $25.5 \%$ of E. coli were resistant to trimethoprim-sulfamethoxazole, $17 \%$ to ofloxacin, $5.6 \%$ to cefixime and $2.2 \%$ to nitrofurantoin. ${ }^{5}$ In an Australian study, $42 \%$ of E. coli were resistant to ampicillin and $21 \%$ to trimethoprim. Over the 5-years of that study there was a concerning increase in resistance to other commonly-used antibiotics. ${ }^{3}$

Guidelines recommend use of antibiotics for UTI. However, in the context of increasing antibiotic resistance it is important to promote judicious use. Antibiotic stewardship might entail: courses of 
antibiotics for no longer than needed, ${ }^{10}$ not prescribing antibiotics if there isn't a UTI (involving decisions regarding empirical treatment versus waiting for confirmation), and 'getting the antibiotic right' first time. ${ }^{11}$

Local patterns of UTI microbial aetiology, antimicrobial resistance and resource availabilities will determine the choice of antibiotic for treatment of UTI recommended by local evidence-based guidelines. In Australia the authoritative guidelines are the national 'Therapeutic Guidelines: Antibiotic' which are usually accessed electronically (eTG). ${ }^{12}$

Early-career general practitioners include specialist trainees in general practice - called 'GPregistrars' in Australia. These GP-registrars are in their first 18 months of clinical general practice and are at a formative phase in establishing their prescribing practices. They have prescribing rights equivalent to established GPs and considerable autonomy of practice, though with access to advice from their clinical supervisor on request. There is evidence that earlier career antibiotic prescribing patterns persist into later practice. ${ }^{13}$ There is no existing evidence regarding the management practices of early-career GPs for UTI.

We aimed to describe the prevalence of clinically diagnosed new UTI presentations to GP-registrars; the proportion of new UTIs for which antibiotics were prescribed at the index consultation (and the associations of an antibiotic being prescribed); the specific antibiotics prescribed; and the proportion of new UTIs for which a mid-stream urine microscopy/culture/sensitivity (MSU) was ordered at the index consultation.

This article is protected by copyright. All rights reserved. 


\section{Methods}

\section{Participants}

This was a cross-sectional analysis of data from the Registrar Clinical Encounters in Training (ReCEnT) cohort study. Data were from 14 rounds of data collection, 2010-16. The study methodology has been described in detail elsewhere. ${ }^{14}$ Briefly, ReCEnT is an ongoing cohort study of GP-registrars' inpractice clinical experiences undertaken (2010-2015) in five of Australia's then seventeen Regional Training Providers (RTPs) across five states, and (in 2016) in three of Australia's current nine Regional Training Organisations (RTOs) across three states. These encompass major city, regional, remote and very remote practices. In this report, RTOs/RTPs will be referred to as 'regions'.

\section{Procedures}

Participating GP-registrar characteristics (at baseline) and the characteristics of their current training practice (in each six-month training term) are documented. GP-registrars then record the details of sixty consecutive office-based consultations (representing approximately one week of consultations) once in each of three compulsory six-month general-practice-based training terms (at approximately mid-term).

\section{Outcome factors}

The primary outcome factor was whether an antibiotic was prescribed at the index consultation for a 'new UTI' problem/diagnosis. Secondary outcome factors were a problem/diagnosis being a UTI (versus a non-UTI problem/diagnosis); the specific antibiotic prescribed for a 'new UTI' problem/diagnosis; and whether a mid-stream urine microscopy/culture/sensitivity (MSU) was requested for a 'new UTI' problem/diagnosis.

This article is protected by copyright. All rights reserved. 
'New UTI' was a clinical problem/diagnosis made by the GP-registrar and recorded as being 'new' at the time of the index consultation. This definition included new episodes of UTI even if the patient had a history of previous UTIs. GP-registrars were requested to record provisional diagnoses (in the case of UTIs this would include presumptive UTI even if awaiting MSU result for confirmation). Problems/diagnoses addressed in the consultation were coded according to the International Classification of Primary Care, second edition (ICPC-2).(14) UTI problems/diagnoses were defined by ICPC-2 codes beginning U71 (cystitis/urinary infection) and U70 (pyelonephritis/pyelitis), excluding U71002 (trigonitis), U71003 (bacteriuria), U71005 (chronic cystitis), U71024 (interstitial cystitis), and U70007 (renal abscess).

Medications prescribed were classified using the Anatomic Therapeutic Chemical (ATC) Classification $\operatorname{codes}^{15}$ with antibiotics defined by the medications code 'J01'.

\section{Independent variables}

Explanatory variables related to patient, GP-registrar, practice and consultation factors.

Patient factors were age, gender, Aboriginal or Torres Strait Islander status, non-English-speaking background (NESB) status, and whether the patient was a new patient for the GP-registrar or practice.

GP-registrar factors were age, gender, FTE status, training term, place of medical qualification (Australia or international), region (RTP/RTO enrolled with), and whether they had worked at the practice in previous terms.

Practice factors were practice size (full-time equivalent number of GPs), routinely bulk-bills (that is, there is no financial cost to the patient for the consultation), rurality, and socio-economic status of 
the practice location. Practice postcode was used to define the Australian Standard Geographical Classification-Remoteness Area (ASGC-RA) classification ${ }^{16}$ (the degree of rurality) and the Socioeconomic Index for Areas (SEIFA) Index of Disadvantage ${ }^{17}$ of the practice location.

Consultation factors were duration of consultation, number of problems/diagnoses dealt with, pathology or imaging ordered, referral made, whether the GP-registrar sought clinical information or assistance during the consultation (from their GP supervisor, a specialist, other health professional, or from electronic or hard-copy resources), whether a follow-up consultation was ordered, and whether they generated any 'learning goals' (clinical questions to be pursued after the consultation had finished).

Data Analysis

Analyses were at the level of the problem/diagnosis and were interpreted in relation to the eTG that were current at the time of collecting data.

The proportion of all problems/diagnoses that were a new UTI was calculated with $95 \%$ Confidence Interval $(95 \% \mathrm{Cl})$.

In analyses confined to those problems classified as a new UTI, univariate and multivariable logistic regressions were conducted to determine the associations of prescribing an antibiotic. Logistic regression was used within the generalised estimating equations (GEE) framework to account for repeated measures within GP-registrars. An exchangeable working correlation structure was assumed. Covariates with a $\mathrm{p}$-value $<0.20$ in the univariate analysis were considered for inclusion in the multivariable regression model. Covariates which were no longer significant $(a t p<0.20)$ in the multivariable model were removed from the final model providing the covariate's removal did not substantively change the resulting model.

This article is protected by copyright. All rights reserved. 
The proportions of individual antibiotics prescribed for new UTIs at the index consultation were calculated. The proportion of new UTIs for which an MSU was ordered and for which antibiotics were prescribed at the index consultation were calculated with $95 \% \mathrm{Cls}$.

In post hoc analyses, the proportions of each source of in-consultation information or assistance, the proportion of MSU ordered and antibiotic prescribed for treatment subgroups in the eTG (females aged 16 years or older, males aged 16 years or older, all children aged under 16 years), and the proportion of new UTIs for which neither an antibiotic was prescribed nor an MSU requested were calculated.

Analyses were programmed using Stata 13.1 (Statacorp, College Station, TX, USA) and SAS V9.4 (SAS Institute Inc., Cary, NC, USA).

Ethics approval

The ReCEnT project has approval from the University of Newcastle Human Research Ethics Committee, Reference H-2009-0323.

\section{Results}

1,333 GP-registrars (response rate $95.8 \%$ ) contributed data from 189,736 consultations comprising 3,195 registrar-rounds of data collection. The characteristics of GP-registrars and their practices are presented in Table 1. There were 293,824 problems/diagnoses recorded. Patients with a new UTI $(n=2,850)$ represented $0.97 \%$ [95\% $\mathrm{Cl} 0.94-1.01]$ of all problems/diagnoses in $1.5 \%$ [95\% $\mathrm{Cl} 1.4-1.6]$ of consultations. New UTI represented 2,186 (1.4\% [95\%Cl 1.3-1.5]) problems for females aged 16 years and over, $211(0.25 \%$ [95\% $\mathrm{Cl} 0.22-0.28])$ problems for males aged 16 years and over, and 365

This article is protected by copyright. All rights reserved. 
$(0.85 \%$ [95\% Cl $0.76-0.94])$ problems for patients aged under 16 years. Of 2,850 patients with a new UTI, $2,461(86.4 \%$ [95\% $\mathrm{Cl} 85.0-87.6]$ were prescribed antibiotics at the index consultation.

Characteristics of consultations involving a new UTI are presented in Table 2. Results for univariate and multivariable modelling are presented in Table 3.

The multivariable model demonstrated several significant associations. Treating a new UTI problem with antibiotics at the index consultation was significantly more likely for adult patients than for children (age under 16). Term 3 GP-registrars, or those whose initial medical qualification was from Australia were more likely to treat a new UTI with antibiotics. GP-registrars seeking in-consultation information or assistance, not making a referral to other health professionals, or addressing fewer problems (than consultations not involving a new UTI) were also more likely when prescribing antibiotics for a new UTI.

In-consultation information or assistance was sought in $427(17.4 \%[95 \% \mathrm{Cl} 15.9-18.9]$ of new UTI where an antibiotic was prescribed. Overwhelmingly the most common source used for inconsultation information/assistance was an electronic source, 343 problems $(80.3 \%$ [95\% Cl $76.3-$ $83.8])$, followed by advice from the supervisor or another doctor in the practice, 69 problems $(16.2 \%$ [95\% $\mathrm{Cl} 13.0-20.0])$. The most common electronic source was the eTG which was used in $68.2 \%$ [95\% $\mathrm{Cl} 63.1-72.8]$ of instances of electronic information/assistance seeking.

The proportions of individual antibiotics prescribed for a new UTI are shown in Table 4. These proportions follow the order of choices recommended by the eTG for treatment of UTI in adult women and men. For children, the eTG recommends trimethoprim containing medications first followed by cefalexin, but that order is reversed in our data. The other antibiotic choices follow the order recommended by the eTG.

This article is protected by copyright. All rights reserved. 
An MSU was ordered in 1,702 (77.9\% [95\% Cl 76.1-79.6]) of new UTI problems/diagnoses in females aged 16 years or older, $146(69.2 \%$ [95\%Cl 62.6-75.1]) for males aged 16 years or older, and 295 (80.8\% [95\% Cl 76.4-84.6]) for patients under 16 years old.

An antibiotic was prescribed at the index consultation in 1,936 (88.6\% [95\% $\mathrm{Cl} 87.2-89.8])$ of problems for a new UTI in females aged 16 years or older, 174 (82.5\% [95\%CI 76.7-87.1]) for males aged 16 years or older, and 275 (75.3\% [95\%Cl 70.6-79.5]) for patients under 16 years of age. No MSU was ordered and no antibiotics were prescribed at the index consultation in $43(2.0 \%$ [95\% Cl 1.5-2.6]) of new UTI in females aged 16 years or older, $14(6.6 \%$ [95\% Cl 4.0-10.9]) for males aged 16 years or older, and $11(3.0 \%$ [95\% $\mathrm{Cl} 1.7-5.4])$ for all patients under 16 years old. Of this total of 72 problems, 37 had some other action(s) taken: 23 had specific follow-up arranged in the practice, 11 had other pathology tests and imaging ordered, 4 were referred to the emergency department, 4 were treated with a urine alkaliniser, 1 was referred for urologist review.

\section{Discussion}

We found UTI to be a frequent problem, being seen in $1.5 \%$ of consultations, comparable with established Australian GPs' practice who manage a new UTI in $1.2 \%$ of consultations. ${ }^{1}$

Our finding that $86.4 \%$ of all new UTIs prompted an antibiotic prescription at the index consultation is consistent with the eTG recommendation of empirical antibiotic treatment for UTI.

However, an antibiotic being prescribed for a new UTI at the index consultation was significantly more likely for adults than for children. An antibiotic was only prescribed at $75.3 \%$ of consultations with children. Since there are practical barriers to obtaining a urine sample from younger children at 
the index consultation, it is possible that prescription of antibiotics may sometimes have been deferred until more data was available to guide decision-making.

Associations with consultations involving fewer problems managed and with not being referred are consistent with a new UTI often being an acute uncomplicated problem that is confidently treated in primary care. The finding, however, that GP-registrars are more likely to treat with antibiotics in their final training term likely reflects some degree of clinical uncertainty in diagnosis in earlier terms which attenuates with increasing experience in the general practice setting.

Our data showed that empiric antibiotic choice followed the eTG recommendations for each group considered (women $>=16$ years, men $>=16$ years, children $<16$ ).${ }^{12}$ We do not have the data to comment on UTI in pregnant women but we would expect a similar concordance with guidelines based upon our findings in the other groups. This adherence to guidelines is supported by the positive association with in-consultation information-seeking for new UTI. When in-consultation help was sought (17.4\% of all new UTI consultations) the substantial majority used the eTG.

There was some use of amoxicillin alone as empiric treatment in each group. It is not a recommended choice for empirical therapy. This was most prevalent in children (6.7\%) and points to an evidence-practice gap that could be addressed by targeted education of early-career GPs while their prescribing habits are becoming established.

Also, there was a high proportion of ordering an MSU in each group analysed. For women $>=16$ years it was $77.9 \%$ but the eTG advises that an MSU is not mandatory for uncomplicated cystitis in nonpregnant women (it is mandatory in pregnant women). This high proportion of MSU may reflect concerns about antibiotic resistance which is known to be increasing in the community. ${ }^{3}$ For men $>=16$ years, MSU was ordered in $69.2 \%$ but the eTG recommends that all men with suspected UTI 
should have an MSU (all UTI are considered as complex in males). For children under 16 years our early-career GPs ordered an MSU in $80.8 \%$ even though the eTG recommends that an MSU is mandatory in this group whenever UTI is suspected. These results may also indicate an evidencepractice gap that could be addressed by education. But they could also reflect the relatively greater difficulty in making a diagnosis of UTI in children and in obtaining a urine sample for dipstick testing in younger children. That is, our findings may reflect a temporal disconnect of provisional diagnosis and antibiotic prescription - between index and subsequent consultations - with clinical uncertainty leading to delay in prescribing while awaiting diagnostic confirmation. This may also be the case in male patients where the pre-test probability of UTI may frequently be lower than in female patients. Of the 72 problems where no antibiotic was prescribed and no MSU ordered at the consultation, 37 had some form of appropriate action taken that is consistent with a review appointment of a prior undiagnosed problem. In the remaining cases, it is possible that symptoms were resolving at the time of the index consultation and patients elected a conservative course of action (fluid intake/urine alkalinisation/non-steroidal anti-inflammatory) for the presumptive UTI. It is also possible that actions taken in the remaining cases may not have been recorded in our data collection method (for example, the patient already having taken 'standby' medication but still presenting for review or for work/carers certificate etc).

\section{Limitations and Strengths}

Our study's high response rate, unusual for studies in general practice, ${ }^{18}$ is a strength.

A limitation is our reliance upon the GP-registrar identifying a problem as a new UTI, and so our estimate of prevalence of new UTI presentations is subject to risk of misdiagnosis. UTI is usually a straightforward diagnosis and this risk is likely to be modest. However, our findings of compliance 
with recommended investigation and management are robust given that these depend upon the diagnosis at the time of the consultation, and that we have consultation-level documentation of the actual management choices made by the GP-registrars.

Our methodology does not identify which patients were pregnant and does not include aged-care residents, which means we are unable to comment on adherence to the eTG recommendations for those groups. We are unable to account for patients who may not need a new antibiotic prescription written at the index consultation, for example having used a pre-existing prescription held on 'standby' for recurrent UTI, or a repeat prescription from previous UTI treatment. Although our methodology calls for participants to record medications which are recommended be taken even if no prescription is written at the index consultation, adherence to this may not be as stringent as to recording of prescribed medicines. This may explain a proportion of new UTI where an antibiotic prescription was not written.

Implications for practice and further research

Even though our early-career general practitioners seem to adhere to guidelines for the management of acute uncomplicated UTIs, it is unclear if the recommendations regarding duration and dose are followed. Also, the broad range of antibiotics recommended in guidelines may not serve antimicrobial stewardship efforts.

The association of non-prescription of antibiotics at the index consultation with children and male adults may reflect delayed prescribing (awaiting diagnostic conformation) consequent upon clinical uncertainty in these harder-to-diagnose or lower pre-test probability groups. This may, in turn, reflect prudent antibiotic stewardship - avoiding antibiotics in situations not requiring them. There 
is, however, evidence that delaying antibiotic commencement in UTIs may result in higher risk of pyelonephritis, ${ }^{6-8}$ and bloodstream infection and all-cause mortality in the elderly. ${ }^{9}$

Thus, antibiotic prescribing in suspected UTIs may not always be as straightforward as is assumed. In this situation, there is scope for qualitative research to understand the decision-making regarding ordering an MSU and prescribing an antibiotic for new UTI in children and males 16 years or older.

\section{Conclusion}

A new UTI is a common presentation for Australian early-career GPs and occurs with a similar frequency to established GPs in Australia. Further research is needed to understand some decisions made when managing UTI in children and adult men. However, early career general practitioners have demonstrated adherence to Australian guidelines for antibiotic choice in UTI.

\section{References}

1. Britt H, Miller GC, Henderson J, et al. General practice activity in Australia 2015-16. General practice series no. 40. Sydney 2016.

2. Foxman B. Urinary tract infection syndromes: occurrence, recurrence, bacteriology, risk factors, and disease burden. Infect Dis Clin North Am. 2014;28(1):1-13.

This article is protected by copyright. All rights reserved. 
3. Fasugba O, Mitchell BG, Mnatzaganian G, Das A, Collignon P, Gardner A. Five-Year Antimicrobial Resistance Patterns of Urinary Escherichia coli at an Australian Tertiary Hospital: Time Series Analyses of Prevalence Data. PLoS One. 2016;11(10):e0164306.

4. Kahlmeter G. An international survey of the antimicrobial susceptibility of pathogens from uncomplicated urinary tract infections: the ECO.SENS Project. Journal of Antimicrobial Chemotherapy. 2002;51(1):69-76.

5. Malmartel A, Ghasarossian C. Epidemiology of urinary tract infections, bacterial species and resistances in primary care in France. Eur J Clin Microbiol Infect Dis. 2016;35(3):447-451.

6. Bleidorn J, Hummers-Pradier E, Schmiemann G, Wiese B, Gágyor I. Recurrent urinary tract infections and complications after symptomatic versus antibiotic treatment: follow-up of a randomised controlled trial. GMS German Medical Science. 2016;14.

7. Gagyor I, Bleidorn J, Kochen MM, Schmiemann G, Wegscheider K, Hummers-Pradier E. Ibuprofen versus fosfomycin for uncomplicated urinary tract infection in women: randomised controlled trial. BMJ. 2015;351:h6544.

8. Kronenberg A, Butikofer L, Odutayo A, et al. Symptomatic treatment of uncomplicated lower urinary tract infections in the ambulatory setting: randomised, double blind trial. BMJ. 2017;359:j4784.

9. Gharbi $\mathrm{M}$, Drysdale $\mathrm{JH}$, Lishman $\mathrm{H}$, et al. Antibiotic management of urinary tract infection in elderly patients in primary care and its association with bloodstream infections and all cause mortality: population based cohort study. BMJ. 2019;364:1525.

This article is protected by copyright. All rights reserved. 
10. Dawson-Hahn EE, Mickan S, Onakpoya I, et al. Short-course versus long-course oral antibiotic treatment for infections treated in outpatient settings: a review of systematic reviews. Fam Pract. 2017;34(5):511-519.

11. Little P, Moore MV, Turner S, et al. Effectiveness of five different approaches in management of urinary tract infection: randomised controlled trial. BMJ. 2010;340:c199.

12. eTG Complete. Urinary Tract Infections [Internet]. . https://tgldcdp.tg.org.au/viewTopic?topicfile=urinary-tractinfections\&guidelineName=Antibiotic\#toc_d1e751.

13. Bjornsdottir I, Kristinsson KG, Hansen EH. Diagnosing infections: a qualitative view on prescription decisions in general practice over time. Pharm World Sci. 2010;32(6):805-814.

14. Morgan S, Magin PJ, Henderson KM, et al. Study protocol: the Registrar Clinical Encounters in Training (ReCEnT) study. BMC Fam Pract. 2012;13:50.

15. WHO Collaborating Centre for Drug Statistics Methodology. Anatomical Therapeutic Chemical (ATC) classification system. Structure and principles.

http://www.whocc.no/atc/structure_and_principles/.

16. Australian Standard Geographical Classification (ASGC) - 2006. at http://www.abs.gov.au/AUSSTATS/abs@.nsf/Latestproducts/1AE106C101420508CA2571A90017074 $1:($ accessed 8/6/15). 2006.

17. AustralianBureauofStatistics. 2039.0 - Information Paper: An Introduction to Socio-economic Indexes of Areas (SEIFA), 2006. Available at: http://www.abs.gov.au/ausstats/abs@.nsf/mf/2039.0/ [accessed 8/6/15]. 2006.

This article is protected by copyright. All rights reserved. 
18. Bonevski B, Magin P, Horton G, Foster M, Girgis A. Trialling two recruitment strategies for improving response rates in general practitioner surveys: mission impossible. Aust Fam Physician. 2011;40:427-430.

\section{Acknowledgements}

The authors would like to thank the GP-registrars and practices who participated in ReCEnT.

\section{Conflict of Interest}

The authors declare no conflicts of interest.

\section{Funding}

This work was supported by government funding as follows. During the data collection period included in this study, funding of the ReCEnT study was by the participating educational organizations: General Practice Training Valley to Coast, the Victorian Metropolitan Alliance, General Practice Training Tasmania, Tropical Medical Training, and Adelaide to Outback GP Training Program (2010-2015). These organizations were funded by the Australian Department of Health. During 201618, the ReCEnT study was funded by an Australian Commonwealth Department of Health Research Grant and supported by GP Synergy, the general practice Regional Training Organization for New South Wales and the Australian Capital Territory. GP Synergy is funded by the Australian Department of Health. 


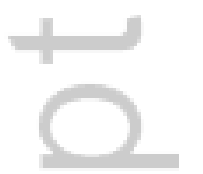

4 
Table 1: Demographics of participating GP-registrars and their practices.

\begin{tabular}{|c|c|c|}
\hline Variable & Class & n (\%) \\
\hline \multicolumn{3}{|l|}{ Registrar variables ( $n=1333)$} \\
\hline Gender & Male & $462(34.7)$ \\
\hline Qualified as a doctor in Australia & Yes & $1064(80.5)$ \\
\hline Pathway & General & $968(73.2)$ \\
\hline \multicolumn{3}{|c|}{ Registrar-term or practice-term variables $(n=3195)$} \\
\hline \multirow[t]{3}{*}{ Registrar training term } & Term 1 & $1233(38.6)$ \\
\hline & Term 2 & $1140(35.7)$ \\
\hline & Term 3 & $822(25.7)$ \\
\hline Registrar age (years) & Mean (SD) & $32.6(6.3)$ \\
\hline Registrar worked at practice previously & Yes & $837(26.6)$ \\
\hline Registrar works full-time & Yes & $2418(77.6)$ \\
\hline Practice routinely bulk bills & Yes & $561(17.9)$ \\
\hline Number of GPs working at practice & 5 or more & $2045(65.8)$ \\
\hline \multirow[t]{3}{*}{ Rurality of practice } & Major city & $1833(57.4)$ \\
\hline & Inner regional & $839(26.3)$ \\
\hline & $\begin{array}{l}\text { Outer regional } \\
\text { or remote }\end{array}$ & $519(16.3)$ \\
\hline SEIFA (decile) of practice & Mean (SD) & $5.6(2.9)$ \\
\hline
\end{tabular}

This article is protected by copyright. All rights reserved. 
Table 2: Characteristics of antibiotic prescribing in index consultations involving a new UTI

\begin{tabular}{|c|c|c|c|c|c|}
\hline Factor group & Variable & Class & $\begin{array}{c}\text { No antibiotic } \\
\text { prescribed }\end{array}$ & $\begin{array}{l}\text { Antibiotic } \\
\text { prescribed }\end{array}$ & $\mathbf{P}$ \\
\hline \multirow[t]{10}{*}{ Patient factors } & Patient age/gender & $<16 y r s$ & $90(24 \%)$ & 275 (12\%) & $<0.001$ \\
\hline & & Males $>=16$ years & $37(10 \%)$ & $174(7 \%)$ & \\
\hline & & Females $>=16$ years & $250(66 \%)$ & 1936 (81\%) & \\
\hline & $\begin{array}{l}\text { Aboriginal or Torres Strait } \\
\text { Islander }\end{array}$ & No & 360 (99\%) & 2297 (99\%) & 0.68 \\
\hline & & Yes & $5(1 \%)$ & $28(1 \%)$ & \\
\hline & NESB $\#$ & No & $350(94 \%)$ & 2206 (94\%) & 0.91 \\
\hline & & Yes & $23(6 \%)$ & $138(6 \%)$ & \\
\hline & Patient/practice status & Existing patient & $135(36 \%)$ & $759(31 \%)$ & 0.04 \\
\hline & & New to registrar & 207 (55\%) & $1474(61 \%)$ & \\
\hline & & New to practice & $37(10 \%)$ & $178(7 \%)$ & \\
\hline \multirow[t]{12}{*}{ Registrar factors } & Registrar gender & Male & $110(28 \%)$ & $741(30 \%)$ & 0.43 \\
\hline & & Female & $279(72 \%)$ & $1720(70 \%)$ & \\
\hline & $\begin{array}{l}\text { Registrar Full Time or Part } \\
\text { Time }\end{array}$ & Part-time & $93(24 \%)$ & $558(23 \%)$ & 0.59 \\
\hline & & Full-time & $288(76 \%)$ & 1857 (77\%) & \\
\hline & Term & Term 1 & $163(42 \%)$ & $940(38 \%)$ & 0.18 \\
\hline & & Term 2 & $144(37 \%)$ & $886(36 \%)$ & \\
\hline & & Term 3 & $82(21 \%)$ & $635(26 \%)$ & \\
\hline & $\begin{array}{l}\text { Worked at practice } \\
\text { previously }\end{array}$ & No & $274(72 \%)$ & $1794(74 \%)$ & 0.53 \\
\hline & & Yes & $106(28 \%)$ & $633(26 \%)$ & \\
\hline & $\begin{array}{l}\text { Qualified as doctor in } \\
\text { Australia }\end{array}$ & No & $112(29 \%)$ & $518(21 \%)$ & 0.003 \\
\hline & & Yes & $274(71 \%)$ & 1923 (79\%) & \\
\hline & Registrar age & mean (SD) & $34(7)$ & $32(6)$ & 0.002 \\
\hline \multirow[t]{3}{*}{ Practice factors } & Practice size & Small & $122(32 \%)$ & $786(33 \%)$ & 0.36 \\
\hline & & Large & $260(68 \%)$ & 1624 (67\%) & \\
\hline & Practice routinely bulk bills & No & $309(81 \%)$ & 2049 (85\%) & 0.16 \\
\hline
\end{tabular}




\begin{tabular}{|c|c|c|c|c|c|}
\hline Factor group & Variable & Class & $\begin{array}{l}\text { No antibiotic } \\
\text { prescribed }\end{array}$ & $\begin{array}{l}\text { Antibiotic } \\
\text { prescribed }\end{array}$ & $\mathbf{P}$ \\
\hline & & Yes & $72(19 \%)$ & $374(15 \%)$ & \\
\hline & Rurality & Major city & 206 (53\%) & 1403 (57\%) & 0.28 \\
\hline & & Inner regional & $129(33 \%)$ & $722(29 \%)$ & \\
\hline & & $\begin{array}{l}\text { Outer regional/ } \\
\text { remote }\end{array}$ & $54(14 \%)$ & 335 (14\%) & \\
\hline & Region & Region 1 & $131(34 \%)$ & $738(30 \%)$ & 0.07 \\
\hline & & Region 2 & $63(16 \%)$ & $284(12 \%)$ & \\
\hline & & Region 3 & $45(12 \%)$ & $306(12 \%)$ & \\
\hline & & Region 4 & $140(36 \%)$ & $1052(43 \%)$ & \\
\hline & & Region 5 & $10(3 \%)$ & $81(3 \%)$ & \\
\hline & SEIFA* index & mean (SD) & $6(3)$ & $6(3)$ & 0.12 \\
\hline \multirow[t]{15}{*}{ Consultation factors } & Chronic problem & No & 389 (100\%) & $2461(100 \%)$ & \\
\hline & Sought help any source & No & 342 (88\%) & $2034(83 \%)$ & 0.01 \\
\hline & & Yes & 47 (12\%) & 427 (17\%) & \\
\hline & Pathology ordered & No & $79(20 \%)$ & $504(20 \%)$ & 0.90 \\
\hline & & Yes & $310(80 \%)$ & $1957(80 \%)$ & \\
\hline & Imaging ordered & No & $374(96 \%)$ & 2359 (96\%) & 0.87 \\
\hline & & Yes & $15(4 \%)$ & $102(4 \%)$ & \\
\hline & Follow-up ordered & No & $162(42 \%)$ & $1137(46 \%)$ & 0.30 \\
\hline & & Yes & $227(58 \%)$ & $1324(54 \%)$ & \\
\hline & Learning goals generated & No & $324(89 \%)$ & $2149(92 \%)$ & 0.17 \\
\hline & & Yes & 39 (11\%) & $195(8 \%)$ & \\
\hline & Referral ordered & No & $369(95 \%)$ & 2427 (99\%) & $<0.001$ \\
\hline & & Yes & $20(5 \%)$ & $34(1 \%)$ & \\
\hline & Consultation duration & mean $(S D)$ & $21(11)$ & $18(8)$ & $<0.001$ \\
\hline & Number of problems & mean (SD) & $2(1)$ & $2(1)$ & $<0.001$ \\
\hline
\end{tabular}

* Socioeconomic Index for Areas of Disadvantage

\# Non-English-Speaking Background

This article is protected by copyright. All rights reserved. 


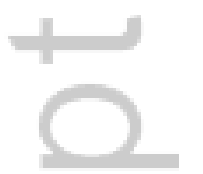

4 
Table 3: Associations with an antibiotic being prescribed at the index consultation for a new UTI

\begin{tabular}{|c|c|c|c|c|c|c|}
\hline \multirow[b]{2}{*}{ Factor group } & \multirow[b]{2}{*}{ Variable } & \multirow[b]{2}{*}{ Class } & \multicolumn{2}{|l|}{ Univariate } & \multicolumn{2}{|l|}{ Adjusted $^{*}$} \\
\hline & & & OR $(95 \% \mathrm{Cl})$ & $\mathbf{P}$ & OR $(95 \% \mathrm{Cl})$ & p \\
\hline Patient factors & $\begin{array}{l}\text { Patient age/gender (referent: } \\
\text { children }<16 \text { years) }\end{array}$ & Females $>=16$ years & $2.46(1.87,3.24)$ & $<0.001$ & $3.53(2.53,4.92)$ & $<0.01$ \\
\hline & & Males $>=16$ years & $1.52(1.00,2.30)$ & 0.05 & $2.14(1.33,3.44)$ & 0.002 \\
\hline Registrar factors & Term (referent: Term 1) & Term 2 & $1.06(0.82,1.36)$ & 0.67 & $1.12(0.85,1.48)$ & 0.43 \\
\hline & & Term 3 & $1.31(0.98,1.74)$ & 0.07 & $1.51(1.09,2.09)$ & 0.01 \\
\hline & Qualified as doctor in Australia & Yes & $1.52(1.15,2.00)$ & 0.003 & $1.66(1.20,2.28)$ & 0.002 \\
\hline actice factors & Practice routinely bulk bills & Yes & $0.80(0.59,1.09)$ & 0.16 & $0.78(0.55,1.10)$ & 0.15 \\
\hline & Region (referent: Region 1) & Region 2 & $0.82(0.55,1.22)$ & 0.33 & $0.73(0.47,1.14)$ & 0.17 \\
\hline & & Region 3 & $1.22(0.83,1.79)$ & 0.31 & $1.32(0.84,2.09)$ & 0.23 \\
\hline & & Region 4 & $1.34(1.01,1.77)$ & 0.04 & $1.18(0.85,1.63)$ & 0.33 \\
\hline & & Region 5 & $1.49(0.77,2.88)$ & 0.24 & $1.26(0.60,2.65)$ & 0.54 \\
\hline Consultation factors & Sought information/assistance & Yes & $1.49(1.08,2.04)$ & 0.01 & $2.38(1.62,3.49)$ & $<0.001$ \\
\hline & Learning goals generated & Yes & $0.78(0.54,1.11)$ & 0.17 & $0.87(0.57,1.32)$ & 0.51 \\
\hline & Referral ordered & Yes & $0.28(0.15,0.51)$ & $<0.001$ & $0.33(0.15,0.72)$ & 0.006 \\
\hline & Consultation duration & & $0.96(0.95,0.98)$ & $<0.001$ & $0.99(0.97,1.00)$ & 0.12 \\
\hline & Number of problems & & $0.62(0.56,0.69)$ & $<0.001$ & $0.61(0.53,0.70)$ & $<0.001$ \\
\hline
\end{tabular}

* Hosmer-Lemeshow chi $=28.27 \mathrm{p}=0.058$, indicating the model was a good fit. The c-statistic for the analysis was 0.727 , indicating a good model. 
Table 4: Most common antibiotics prescribed for a new UTI

\begin{tabular}{|l|l|l|l|}
\hline Anitbiotic & $\begin{array}{l}\text { Female 16 years } \\
\text { and older } \\
\mathbf{n = 1 , 9 3 8}(\%)\end{array}$ & $\begin{array}{l}\text { Male 16 years } \\
\text { and older } \\
\mathbf{n = 1 7 6}(\%)\end{array}$ & $\begin{array}{l}\text { All under 16 } \\
\text { years old } \\
\mathbf{n = 2 8 0}(\%)\end{array}$ \\
\hline Trimethoprim & $1016(50.1)$ & $80(45.2)$ & $41(14.5)$ \\
\hline Cefalexin & $699(34.9)$ & $57(32.2)$ & $166(58.7)$ \\
\hline amoxicillin and enzyme inhibitor & $118(5.9)$ & $23(13.0)$ & $23(8.1)$ \\
\hline Amoxicillin & $34(1.7)$ & $5(2.8)$ & $19(6.7)$ \\
\hline Nitrofurantoin & $31(1.6)$ & $1(0.6)$ & $5(1.8)$ \\
\hline Norfloxacin & $23(1.2)$ & $5(2.8)$ & 0 \\
\hline $\begin{array}{l}\text { sulfamethoxazole and } \\
\text { trimethoprim }\end{array}$ & $6(0.3)$ & $2(1.1)$ & $16(5.7)$ \\
\hline
\end{tabular}

= Empiric antibiotic choice recommended by eTG (electronic Therapeutic Guidelines) 
Table 1: Demographics of participating GP-registrars and their practices.

\begin{tabular}{|c|c|c|}
\hline Variable & Class & n (\%) \\
\hline \multicolumn{3}{|l|}{ Registrar variables ( $n=1333)$} \\
\hline Gender & Male & $462(34.7)$ \\
\hline Qualified as a doctor in Australia & Yes & $1064(80.5)$ \\
\hline Pathway & General & 968 (73.2) \\
\hline \multicolumn{3}{|c|}{ Registrar-term or practice-term variables $(n=3195)$} \\
\hline \multirow[t]{3}{*}{ Registrar training term } & Term 1 & $1233(38.6)$ \\
\hline & Term 2 & $1140(35.7)$ \\
\hline & Term 3 & $822(25.7)$ \\
\hline Registrar age (years) & Mean (SD) & $32.6(6.3)$ \\
\hline Registrar worked at practice previously & Yes & 837 (26.6) \\
\hline Registrar works full-time & Yes & $2418(77.6)$ \\
\hline Practice routinely bulk bills & Yes & 561 (17.9) \\
\hline Number of GPs working at practice & 5 or more & $2045(65.8)$ \\
\hline \multirow[t]{3}{*}{ Rurality of practice } & Major city & $1833(57.4)$ \\
\hline & Inner regional & 839 (26.3) \\
\hline & $\begin{array}{l}\text { Outer regional } \\
\text { or remote }\end{array}$ & 519 (16.3) \\
\hline SEIFA (decile) of practice & Mean (SD) & $5.6(2.9)$ \\
\hline
\end{tabular}

This article is protected by copyright. All rights reserved. 
Table 2: Characteristics of antibiotic prescribing in index consultations involving a new UTI

\begin{tabular}{|c|c|c|c|c|c|}
\hline Factor group & Variable & Class & $\begin{array}{l}\text { No antibiotic } \\
\text { prescribed }\end{array}$ & $\begin{array}{l}\text { Antibiotic } \\
\text { prescribed }\end{array}$ & $\mathbf{P}$ \\
\hline \multirow[t]{10}{*}{ Patient factors } & Patient age/gender & $<16 y r s$ & $90(24 \%)$ & 275 (12\%) & $<0.001$ \\
\hline & & Males $>=16$ years & $37(10 \%)$ & $174(7 \%)$ & \\
\hline & & Females $>=16$ years & $250(66 \%)$ & 1936 (81\%) & \\
\hline & $\begin{array}{l}\text { Aboriginal or Torres Strait } \\
\text { Islander }\end{array}$ & No & 360 (99\%) & 2297 (99\%) & 0.68 \\
\hline & & Yes & $5(1 \%)$ & $28(1 \%)$ & \\
\hline & $\mathrm{NESB}^{\#}$ & No & $350(94 \%)$ & 2206 (94\%) & 0.91 \\
\hline & & Yes & $23(6 \%)$ & $138(6 \%)$ & \\
\hline & Patient/practice status & Existing patient & $135(36 \%)$ & 759 (31\%) & 0.04 \\
\hline & & New to registrar & $207(55 \%)$ & $1474(61 \%)$ & \\
\hline & & New to practice & $37(10 \%)$ & $178(7 \%)$ & \\
\hline \multirow[t]{12}{*}{ Registrar factors } & Registrar gender & Male & $110(28 \%)$ & $741(30 \%)$ & 0.43 \\
\hline & & Female & $279(72 \%)$ & $1720(70 \%)$ & \\
\hline & $\begin{array}{l}\text { Registrar Full Time or Part } \\
\text { Time }\end{array}$ & Part-time & $93(24 \%)$ & $558(23 \%)$ & 0.59 \\
\hline & & Full-time & $288(76 \%)$ & $1857(77 \%)$ & \\
\hline & Term & Term 1 & $163(42 \%)$ & $940(38 \%)$ & 0.18 \\
\hline & & Term 2 & $144(37 \%)$ & 886 (36\%) & \\
\hline & & Term 3 & $82(21 \%)$ & $635(26 \%)$ & \\
\hline & $\begin{array}{l}\text { Worked at practice } \\
\text { previously }\end{array}$ & No & $274(72 \%)$ & $1794(74 \%)$ & 0.53 \\
\hline & & Yes & $106(28 \%)$ & $633(26 \%)$ & \\
\hline & $\begin{array}{l}\text { Qualified as doctor in } \\
\text { Australia }\end{array}$ & No & $112(29 \%)$ & $518(21 \%)$ & 0.003 \\
\hline & & Yes & $274(71 \%)$ & 1923 (79\%) & \\
\hline & Registrar age & mean $(S D)$ & $34(7)$ & $32(6)$ & 0.002 \\
\hline \multirow[t]{6}{*}{ Practice factors } & Practice size & Small & $122(32 \%)$ & 786 (33\%) & 0.36 \\
\hline & & Large & $260(68 \%)$ & $1624(67 \%)$ & \\
\hline & Practice routinely bulk bills & No & $309(81 \%)$ & 2049 (85\%) & 0.16 \\
\hline & & Yes & $72(19 \%)$ & $374(15 \%)$ & \\
\hline & Rurality & Major city & 206 (53\%) & $1403(57 \%)$ & 0.28 \\
\hline & & Inner regional & $129(33 \%)$ & 722 (29\%) & \\
\hline
\end{tabular}




\begin{tabular}{|c|c|c|c|c|c|}
\hline Factor group & Variable & Class & $\begin{array}{l}\text { No antibiotic } \\
\text { prescribed }\end{array}$ & $\begin{array}{l}\text { Antibiotic } \\
\text { prescribed }\end{array}$ & $\mathbf{P}$ \\
\hline & & $\begin{array}{l}\text { Outer regional/ } \\
\text { remote }\end{array}$ & $54(14 \%)$ & 335 (14\%) & \\
\hline & Region & Region 1 & 131 (34\%) & $738(30 \%)$ & 0.07 \\
\hline & & Region 2 & $63(16 \%)$ & $284(12 \%)$ & \\
\hline & & Region 3 & $45(12 \%)$ & $306(12 \%)$ & \\
\hline & & Region 4 & $140(36 \%)$ & $1052(43 \%)$ & \\
\hline & & Region 5 & $10(3 \%)$ & $81(3 \%)$ & \\
\hline & SEIFA* index & mean (SD) & $6(3)$ & $6(3)$ & 0.12 \\
\hline \multirow[t]{15}{*}{ Consultation factors } & Chronic problem & No & $389(100 \%)$ & $2461(100 \%)$ & \\
\hline & Sought help any source & No & 342 (88\%) & 2034 (83\%) & 0.01 \\
\hline & & Yes & $47(12 \%)$ & $427(17 \%)$ & \\
\hline & Pathology ordered & No & $79(20 \%)$ & $504(20 \%)$ & 0.90 \\
\hline & & Yes & $310(80 \%)$ & $1957(80 \%)$ & \\
\hline & Imaging ordered & No & $374(96 \%)$ & 2359 (96\%) & 0.87 \\
\hline & & Yes & $15(4 \%)$ & $102(4 \%)$ & \\
\hline & Follow-up ordered & No & $162(42 \%)$ & $1137(46 \%)$ & 0.30 \\
\hline & & Yes & 227 (58\%) & $1324(54 \%)$ & \\
\hline & Learning goals generated & No & 324 (89\%) & $2149(92 \%)$ & 0.17 \\
\hline & & Yes & $39(11 \%)$ & $195(8 \%)$ & \\
\hline & Referral ordered & No & $369(95 \%)$ & 2427 (99\%) & $<0.001$ \\
\hline & & Yes & $20(5 \%)$ & $34(1 \%)$ & \\
\hline & Consultation duration & mean (SD) & $21(11)$ & $18(8)$ & $<0.001$ \\
\hline & Number of problems & mean (SD) & $2(1)$ & $2(1)$ & $<0.001$ \\
\hline
\end{tabular}

* Socioeconomic Index for Areas of Disadvantage

\# Non-English-Speaking Background 
Table 3: Associations with an antibiotic being prescribed at the index consultation for a new UTI

\begin{tabular}{|c|c|c|c|c|c|c|}
\hline \multirow[b]{2}{*}{ Factor group } & \multirow[b]{2}{*}{ Variable } & \multirow[b]{2}{*}{ Class } & \multicolumn{2}{|l|}{ Univariate } & \multicolumn{2}{|l|}{ Adjusted $^{*}$} \\
\hline & & & OR $(95 \% \mathrm{Cl})$ & $\mathbf{P}$ & OR $(95 \% \mathrm{Cl})$ & p \\
\hline Patient factors & $\begin{array}{l}\text { Patient age/gender (referent: } \\
\text { children }<16 \text { years) }\end{array}$ & Females $>=16$ years & $2.46(1.87,3.24)$ & $<0.001$ & $3.53(2.53,4.92)$ & $<0.01$ \\
\hline & & Males $>=16$ years & $1.52(1.00,2.30)$ & 0.05 & $2.14(1.33,3.44)$ & 0.002 \\
\hline Registrar factors & Term (referent: Term 1) & Term 2 & $1.06(0.82,1.36)$ & 0.67 & $1.12(0.85,1.48)$ & 0.43 \\
\hline & & Term 3 & $1.31(0.98,1.74)$ & 0.07 & $1.51(1.09,2.09)$ & 0.01 \\
\hline & Qualified as doctor in Australia & Yes & $1.52(1.15,2.00)$ & 0.003 & $1.66(1.20,2.28)$ & 0.002 \\
\hline actice factors & Practice routinely bulk bills & Yes & $0.80(0.59,1.09)$ & 0.16 & $0.78(0.55,1.10)$ & 0.15 \\
\hline & Region (referent: Region 1) & Region 2 & $0.82(0.55,1.22)$ & 0.33 & $0.73(0.47,1.14)$ & 0.17 \\
\hline & & Region 3 & $1.22(0.83,1.79)$ & 0.31 & $1.32(0.84,2.09)$ & 0.23 \\
\hline & & Region 4 & $1.34(1.01,1.77)$ & 0.04 & $1.18(0.85,1.63)$ & 0.33 \\
\hline & & Region 5 & $1.49(0.77,2.88)$ & 0.24 & $1.26(0.60,2.65)$ & 0.54 \\
\hline Consultation factors & Sought information/assistance & Yes & $1.49(1.08,2.04)$ & 0.01 & $2.38(1.62,3.49)$ & $<0.001$ \\
\hline & Learning goals generated & Yes & $0.78(0.54,1.11)$ & 0.17 & $0.87(0.57,1.32)$ & 0.51 \\
\hline & Referral ordered & Yes & $0.28(0.15,0.51)$ & $<0.001$ & $0.33(0.15,0.72)$ & 0.006 \\
\hline & Consultation duration & & $0.96(0.95,0.98)$ & $<0.001$ & $0.99(0.97,1.00)$ & 0.12 \\
\hline & Number of problems & & $0.62(0.56,0.69)$ & $<0.001$ & $0.61(0.53,0.70)$ & $<0.001$ \\
\hline
\end{tabular}

* Hosmer-Lemeshow chi $=28.27 \mathrm{p}=0.058$, indicating the model was a good fit. The c-statistic for the analysis was 0.727 , indicating a good model. 
Table 4: Most common antibiotics prescribed for a new UTI

\begin{tabular}{|l|l|l|l|}
\hline Anitbiotic & $\begin{array}{l}\text { Female 16 years } \\
\text { and older } \\
\mathbf{n = 1 , 9 3 8}(\%)\end{array}$ & $\begin{array}{l}\text { Male 16 years } \\
\text { and older } \\
\mathbf{n = 1 7 6}(\%)\end{array}$ & $\begin{array}{l}\text { All under 16 } \\
\text { years old } \\
\mathbf{n = 2 8 0}(\%)\end{array}$ \\
\hline Trimethoprim & $1016(50.1)$ & $80(45.2)$ & $41(14.5)$ \\
\hline Cefalexin & $699(34.9)$ & $57(32.2)$ & $166(58.7)$ \\
\hline amoxicillin and enzyme inhibitor & $118(5.9)$ & $23(13.0)$ & $23(8.1)$ \\
\hline Amoxicillin & $34(1.7)$ & $5(2.8)$ & $19(6.7)$ \\
\hline Nitrofurantoin & $31(1.6)$ & $1(0.6)$ & $5(1.8)$ \\
\hline Norfloxacin & $23(1.2)$ & $5(2.8)$ & 0 \\
\hline $\begin{array}{l}\text { sulfamethoxazole and } \\
\text { trimethoprim }\end{array}$ & $6(0.3)$ & $2(1.1)$ & $16(5.7)$ \\
\hline
\end{tabular}

= Empiric antibiotic choice recommended by eTG (electronic Therapeutic Guidelines) 


\section{University Library}

\section{- M M N E R VA A gateway to Melbourne's research publications}

Minerva Access is the Institutional Repository of The University of Melbourne

\section{Author/s:}

Davey, A;Tapley, A;Mulquiney, K;van Driel, M;Fielding, A;Holliday, E;Ball, J;Spike, N;FitzGerald, K;Magin, P

Title:

Management of urinary tract infection by early-career general practitioners in Australia.

Date:

2020-12

\section{Citation:}

Davey, A., Tapley, A., Mulquiney, K., van Driel, M., Fielding, A., Holliday, E., Ball, J., Spike, N., FitzGerald, K. \& Magin, P. (2020). Management of urinary tract infection by earlycareer general practitioners in Australia.. J Eval Clin Pract, 26 (6), pp.1703-1710. https:// doi.org/10.1111/jep.13340.

Persistent Link:

http://hdl.handle.net/11343/286781 